\title{
VISIONES ENCONTRADAS SOBRE LA REPÚBLICA RESTAURADA
}

FRANCISCO JAVIER DELGADO AGUILAR

Departamento de Historia/UAA

Laurens Ballard Perry, Juárez y Dfaz. Continuidad y Ruptura en la política mexicana, Universidad Autónoma Metropolitana-Ediciones Era, México, 1996, 430 pp.

Ningún porfirista tiene por qué sentirse anacrónico en el México contemporáneo, aunque los revolucionarios bien podrian tener que volver a plantearse su causa.

Laurens B. Perry

S Laurens B. Perry un libro que analiza de manera profunda y crítica un período fundamental de la historia de México: la década que va del triunfo liberal sobre el imperio de Maximiliano I -1867- al triunfo de la rebelión de Tuxtepec acaudillada por Porfirio Díaz -1876- y que es conocida entre los historiadores como la época de la República Restaurada.

$\mathrm{El}$ autor aborda este período dividiendo su libro en dos partes: en la primera hace un estudio profundo de la práctica política de los gobiernos de la República Restaurada; el de Benito Juárez (1867-1872) y el de Sebastián Lerdo de Tejada (1872-1876). En la segunda parte se analiza el resultado de dicha práctica política: la rebelión de Tuxtepec, su desarrollo y las condiciones que permitieron su triunfo.

Hasta aquí el lector podría pensar que está frente a una historia tradicionalista, ennumeradora de hechos y batallas militares suficientemente estudiados anteriormente por historiadores de la talla de Daniel Cosío Villegas, por mencionar al más conocido. Es tan sólo cuestión de seguir leyendo el libro para darnos cuenta de que no es así y de que Perry es hasta cierto punto un historiador heterodoxo, pues alejándose de la interpretación oficial establece explícitamente, desde el principio del libro, cual es su objetivo: demostrar el fracaso de la ideología política liberal, 
la cual nunca fue la adecuada para resolver los problemas de la atribulada nación mexicana durante todo el siglo XIX.

Desde este momento el autor comienza a alejarse de las interpretaciones tradicionales de la República Restaurada y del liberalismo mexicano, otorgando al lector una visión diferente no sólo de la República Restaurada en sí misma, sino también del papel de liberalismo y, en general, de toda la historia política del país desde 1867 hasta nuestros días.

Una forma de advertir las principales aportaciones de Perry al estudio de la República Restaurada es comparar sus argumentos y su visión de esta época con los argumentos y la visión de uno de los más reputados historiadores que hayan estudiado dicho período: Daniel Cosío Villegas. Esto es interesante no sólo por el hecho de que Cosío Villegas realizó uno de los estudios más profundos y serios del período, sino por la posición de defensa que asumió dicho historiador, para el cual esta época fue un "modelo político a causa de la calidad intelectual y moral de sus dirigentes, la independencia de sus instituciones representativas (el congreso y los tribunales) y el vigor de su prensa libre".

1. Charles A. Hale, "Daniel Cosío Villegas: historiador y liberal", en Daniel Cosío Villegas, Llamadas, El Colegio de México, México,1980, p.7
Hay pues, desde el principio, un rasgo fundamental que aleja la visión de Cosío de la de Perry, pues esta última es una visión más crítica -de hecho hasta cierto punto sombría y fatalista- de la República Restaurada y la ideología liberal de los gobernantes de la época; esto es notorio desde el primer capítulo del libro, en el cual se analiza el abismo que había entre el credo político, económico y social de los liberales -reflejado en buena medida en la Constitución de 1857- y la realidad política, económica y social del país; para Perry las soluciones propuestas por los liberales para sacar a México del atraso en que vivía no sólo eran las más inadecuadas sino que también provocaron una gran inestabilidad en todos los niveles, sobre todo políticamente, pues para poder gobernar efectivamente tanto Juárez como Lerdo tuvieron que alejarse progresivamente de las normas republicanas, democráticas y federalistas plasmadas en la Constitución y construir lo que al autor llama una "maquinaria política" caracterizada por dos rasgos esenciales: el centralismo político y la monopolización del aparato de gobierno. Esto acabó produciendo durante la República Restaurada un estado casi endémico de rebeliones y asonadas militares, producto de la oposición política al gobierno. A final de cuentas éste viene a ser uno de los principales 
argumentos del autor: para poder gobernar efectivamente había que alejarse de los preceptos constitucionales, lo cual ocasionaba invariablemente el desarrollo de una oposición que, viendo cerradas todas las puertas del sistema político optaba por la salida más expedita: la rebelión militar para acceder a los deseados cargos de gobierno.

A partir de esta concepción el autor analiza en los siete capítulos de la primera parte la vida política durante los gobiernos de Juárez y Lerdo, haciendo énfasis no sólo en las prácticas gubernamentales sino, sobre todo, en el resultado de dichas prácticas: el nacimiento y desarrollo de una oposición política que empezó a alzar cabeza casi inmediatamente después del triunfo de los liberales sobre las fuerzas conservadoras en el año de 1867 y que acabó triunfando con la rebelión de Tuxtepec en al año de 1876.

Es notorio que el autor retoma varias de las ideas y argumentos de Cosío Villegas sobre la República Restaurada, sobre todo aquellos referidos a la monopolización del aparato de gobierno y del centralismo político; así, tenemos que Cosío ya hablaba, como Perry, de la cerrazón del golierno o de la pequeñez del grupo gobernante que bajó de Paso del Norte para hacerse cargo de la política nacional; esta "renovación insuficiente para dar ac- ceso al poder a tanto elemento nuevo" fue causa de desesperación y rencor entre la oposición porfirista, sobre todo después de la reelección de Juárez, situación que desembocó en el estallido de la rebelión de la Noria en 1871. Resulta interesante observar también como Cosío matiza lo anterior afirmando que la visión del grupo de Paso del Norte como impenetrable y cerrado no es del todo exacta y que Juárez, durante su primera presidencia, trató de renovar el gabinete "pero sin fortuna". Perry retoma este rasgo de la vida política y a diferencia de Cosío le da una importancia fundamental; la feroz competencia que existía por los cargos de gobierno y la política seguida por el presidente y los gobernadores de monopolizar dichos cargos fueron una de las causas de la crónica inestabilidad política de la época, agravada por una crisis económica que impedía satisfacer las demandas de trabajo remunerado de la población.

Otro importante punto de coincidencia se refiere al federalismo y a la relación estados-gobierno federal. En este punto Cosío Villegas consciente en que durante estos años el federalismo no fue respeta-

2. Daniel Cosío Villegas, "El Bailete", en Enrique Krauze, (compilador), Daniel Cosío Villegas. El historiador liberal, Fondo de Cultura Económica, México, 1984, pp. 51, 52, 56 y 57. 
do por los gobernantes, lo cual es notorio sobre todo en el caso de la presidencia de Sebastián Lerdo de Tejada, el cual, al calibrar "mal los intereses y el modo de la política local, y al tratar de intervenir en ella para consolidar su gobierno" cometió más yerros que aciertos e hizo más enemigos que amigos. ${ }^{3}$ Como en el caso anterior esto se convierte en uno de los argumentos principales de Perry; para él la relación entre federación y estados es básica para comprender el sistema político de la época y señala que el centralismo fue uno de los rasgos principales de los gobiernos de Juárez y Lerdo, los cuales se veían obligados, si querían gobernar efectivamente y mantenerse en el poder, a establecer alianzas políticas con los gobernadores y caciques de las provincias; si el gobernador era fiel al presidente, éste le dejaba hacer en su estado, lo cual significaba la reproducción, en el ámbito local, de la monopolización del aparato de gobierno llevada a cabo a escala federal; en caso de que el gobernador fuera rebelde 0 adicto a alguna facción opositora, el presidente, sintiéndose amenazado, maniobraba para deshacerse del gobernador incómodo. En este punto resaltan muchas de las

3. Daniel Cosío Villegas, "Sebastián Lerdo de Tejada”, en Enrique Krauze, Op. cit., pp. 148, 158. cualidades del libro de Perry; su análisis, por ejemplo, es llevado a cabo desde la perspectiva de la historia regional, tomando en cuenta la realidad política de varios estados de la república, renunciando a una visión centralista y basándose en fuentes de archivo no consultadas con anterioridad; la narración es detallada y meticulosa; el estudio de los documentos es siempre concienzudo y el establecimiento de los hechos riguroso en todos los casos; es notorio, por ejemplo, el minucioso estudio que hace del congreso federal actor político clave a la hora de resolver los conflictos en las provincias-, tomando en cuenta su división en facciones, su intervención en la lucha política estatal, su relación con el presidente, etcétera.

Las discrepancias entre Cosío y Perry comienzan a la hora de estudiar las elecciones durante la República Restaurada; es sabido que Cosío Villegas defendió la limpieza de las elecciones, asegurando que éstas, bien que mal, reflejaban la popularidad de los candidatos y la fuerza y habilidad de las facciones políticas; ${ }^{4}$ para Perry en cambio no hay lugar a dudas de que el fraude electoral era una práctica común y para demostrarlo emprende un

4. Daniel Cosío Villegas, Llamadas, Op. cit., p.62. 
estudio detallado de la legislación y las actividades electorales, ilustrando con ejemplos concretos la multitud de prácticas fraudulentas y la abstención generalizada de la mayoría de la población. La única duda de Perry es qué tan fraudulentas eran las elecciones, aunque de hecho asegura que, junto con la monopolización del aparato político y el centralismo, esta clase de elecciones elitistas, fraudulentas y faccionales, acabaron provocando el dominio del presidente, la dictadura y las continuas insurrecciones.

Todas estas prácticas políticas puestas en marcha por el gobierno de Juárez fueron retomadas y profundizadas por Lerdo de Tejada, el cual recurre a ellas para mantenerse en el poder, avivando así la oposición porfirista a tal grado que Perry asegura que a la hora de la rebelión de Tuxtepec había "muy poco republicanismo verdadero que sacrificar" (p.294).

Con el análisis del gobierno de Lerdo de Tejada el autor termina el estudio de la vida política durante la República Restaurada y da paso al estudio de la rebelión de Tuxtepec; en este punto conviene preguntarnos, para tratar de dejarlo en claro, cuáles son las diferencias entre la visión que da Perry de la República Restaurada y la ofrecida con anterioridad por Cosío Villegas. Al respecto trataremos de demostrar que más allá de la diferencia señalada entre ambos autores acerca de las elecciones y de las coincidencias arriba mencionadas, hay una diferencia conceptual de fondo.

Comencemos señalando que no podemos olvidar los apuntes críticos de Cosío acerca de los hombres y la política de la República Restaurada; la monopolización de los cargos públicos, la intromisión del gobierno central en la vida política de los estados y la constante recurrencia por parte de Juárez y Lerdo al expediente de los poderes extraordinarios son sólo algunos ejemplos de lo que Cosío llama el "relajamiento constitucional" de la República Restaurada; es importante sin embargo resaltar que estas afirmaciones críticas son siempre, de una u otra manera, matizadas por el mismo autor; el ejemplo más claro de esta posición podemos verlo cuando desde su perspectiva crítica Cosío caracteriza a los gobiernos de la República Restaurada como dictatoriales debido a la existencia de un poder excepcional que tenía su origen en la ley y que es "esencialmente transitorio". Líneas más adelante, sin embargo, el mismo Cosío matiza sus afirmaciones y asegura que esta dictadura nunca fue continua ni total, justificando además dicha situación al señalar que "era bien improbable que la ley normal pudiera regir en condiciones bien anormales, como aquellas que le tocó vi- 
vir a México después de las guerras de Reforma e Intervención".

Llegamos así a otro punto clave que nos sirve para entrever la posición de Cosío con respecto a este período de la historia; para él era muy importante encontrar las causas que contribuyeron a la caída de los gobiernos de la República Restaurada, sobre todo tomando en cuenta que durante estos años México estuvo dirigido por un grupo de políticos destacadísimo y brillante, "que ensayaron tercamente hacer vivir al país dentro de la Constitución", logrando que México tuviera, como nunca antes y nunca después, una vida política "sana, robusta y libre", con poderes de gobierno independientes entre sí, gobiernos locales vigorosos y una opinión pública "libre y alerta" que gozaba de una "amplia libertad de expresión".

Con esta visión de la República Restaurada, en donde los elementos positivos pesan más en el balance final que los negativos -que siempre son matizados-, no es de extrañar que Cosío, al emprender la búsqueda de las causas que explican el fin de dicho período lo haya hecho tratan-

5. Daniel Cosío Villegas, "Cavilación sobre la paz", en Alvaro Matute, (compilador), México en el siglo XIX. Fuentes e interpretaciones históricas, LNAM, México, 1993, pp. 302-304.

6. Daniel Cosío Villegas, Llamadas, Op. cit., pp. 62, 95-101. do de encontrar un "maleficio" y un "villano", pues sólo así podría encontrarle sentido al hecho de que a la interrumpida República Restaurada -que simbolizaba el conjunto de cosas buenas que pudieron haber ocurrido y no ocurrieron- le siguiera la época del Porfiriato, caracterizada por el mismo Cosío no ya como una dictadura sino como una tiranía en donde el poder excepcional tiene un origen personal -no legal- y no conoce límite alguno, rompiendo así con toda organización democrática. El "maleficio" para Cosío Villegas fue la herencia que dejaron al país las guerras de Reforma e Intervención y el "villano" no podía ser otro que Porfirio Díaz.

Dicha herencia, por supuesto, era negativa y consistía, entre otras cosas, en la existencia de un partido conservador con "habilidad y experiencia" y de una iglesia y un ejército con una "aureola deslumbrante" que se convirtieron en importantes factores de inestabilidad; un clima político revolucionario, "de verdadera Convención francesa", poco propicio para la conciliación y generador de odios y desconfianzas, sobre todo hacia los ideólogos e intelectuales que dominaban el panorama político; un gobierno sin recursos suficientes para fomentar el progreso económico o acabar con los "grandes feudos regionales" en que estaba dividido el 
país; inseguridad general que impedía el desarrollo económico; un profundo desarraigo de la población, acostumbrada a los tiempos de guerra y, para terminar, una "abundante cosecha" de héroes civiles y militares que exigían compensaciones y puestos que "el país no podía satisfacer" . Toda esta cauda de problemas constituye, para Cosío, el "maleficio" que no pudo conjurar la República Restaurada y que fue el origen de su caída, un "maleficio" -y esto es lo más importante- que no podía ser imputable a la acción de los gobiernos de Juárez y Lerdo; una carga que no era responsabilidad suya y con la que tuvieron que lidiar infructuosamente hasta su caída; esta es la clave del argumento de Cosío: la República Restaurada cayó bajo el peso de una herencia negativa y no debido a una responsabilidad propia.

La anterior situación fue aprovechada por Díaz, el "villano" de la historia, la única "gran figura" de la época que era "irrefrenablemente ambiciosa" y que, sin experiencia ni paciencia política, encabezó una oposición conformada por elementos "sin rango político o intelectual, de una mentalidad oscura, anárquica y con una clara raigambre popular de que carecían los

7. Daniel Cosío Villegas, "La Coreografía", en Enrique Krauze, (compilador), Op. cit., pp. 38-47. demás grupos" ${ }^{8}$ Este fue el grupo al que Cosío bautizó, no sin malicia, como la "generación tuxtepecadora".

Así Cosío Villegas nos entrega una República Restaurada en donde pesan más los elementos positivos que los negativos y que cae sólo gracias a una herencia maligna que no era responsabilidad suya y que fue aprovechada por un militar sin cualidades políticas pero muy ambicioso.

La República Restaurada de Laurens B. Perry es casi la antítesis de la de Cosío Villegas; las diferencias en este caso son de fondo, de concepción general. Perry retoma conceptos que Cosío toca casi de pasada y los convierte en la base de su argumentación principal, ofreciendo un gran cúmulo de pruebas documentales que demuestran que durante la República Restaurada en México un sistema político caracterizado por la monopolización de los cargos de gobierno, la centralización del poder en manos del ejecutivo, la violación continua del sistema federalista y el casi omnipresente fraude electoral. Para Perry, a diferencia de Cosío, lo último que trataron de hacer los gobernantes de la época fue aplicar los principios de la Constitución de 1857, pues si lo hubieran hecho

8. Daniel Cosío Villegas, "La Coreografía" y "El Bailete", en Enrique Krauze, (compilador), Op. cit., pp. 35,36 y $52-54$. 
no habrían podido gobernar efectivamente; en esto consiste, como mencionábamos más arriba, la gran paradoja de los gobiernos de la República Restaurada: para poder gobernar efectivamente había que alejarse de los principios liberales postulados en la Constitución, lo cual provocaba inevitablemente el surgimiento de una oposición política que derivaba, las más de las veces, en la insurrección militar, dando argumentos al gobierno para proseguir con su peculiar pero efectiva manera de hacer política. En este caso la República Restaurada cae a consecuencia del desarrollo de sus contradicciones internas y no, como lo deja ver Cosío Villegas, por culpa de una herencia maligna y exterior con la que haya tenido que lidiar infructuosamente.

Un punto que nos puede servir para reafirmar esta diferencia de concepción entre ambos autores es el que se refiere al de la relación existente entre República Restaurada y Porfiriato. Para Cosío Villegas había, sin duda, una relación de continuidad entre ambas etapas; el hundimiento de la democracia que caracteriza al Porfiriato se había empezado a desarrollar desde la época del "relajamiento constitucional" a fines de la República Restaurada y el poder ejecutivo culmina durante el Porfiriato un proceso de fortalecimiento y sometimiento del Congreso que ya era visible durante los años que van de 1867 a 1876. De esta manera Cosío ve al Porfiriato como la degeneración política de la República Restaurada; hay para él una continuidad "negativa" que tiende a agravar todos los vicios propios del llamado "relajamiento constitucional".

En el caso de Perry la visión es sutilmente diferente; hay también para él una continuidad clara entre ambas épocas. "La pax porfiriana -asegura Perry- se basó en una fructífera continuación de la maquinaria política de la República Restaurada, aumentada en eficiencia por nuevas innovaciones administrativas y tecnológicas". (p. 294. Las cursivas son nuestras). En este caso el autor ve al Porfiriato como el perfeccionamiento de las prácticas políticas de los gobiernos de Juárez y Lerdo y no como una degeneración, tal y como aparece en la visión de Cosío Villegas.

Podemos observar entonces que sí hay diferencias de fondo entre ambos autores y que Perry entabla una discusión más con el historiador moralista que era Cosío Villegas -aquel que hizo una "defensa apasionada de la Constitución del 57 y de la República Restaurada"- que con el historiador con microscopio que también era Cosío y que "escribió la mayor canti-

9. Charles A. Hale, Op. cit., pp. 8 y 9. 
dad de páginas (y) consultó un número pasmoso de documentos". ${ }^{10}$

La concepción desarrollada por Perry acerca de la vida política durante la República Restaurada se ve acompañada, en la segunda parte del libro, por un análisis serio, concienzudo y detallado de la rebelión de Tuxtepec, el principal producto ocasionado por las prácticas políticas de los gobiernos de Juárez y Lerdo. Aquí existe también una distancia clara entre la interpretación de Perry y Cosío Villegas; para Cosío, como para muchos otros historiadores, la rebelión de Tuxtepec triunfó sólo gracias a la división del gobierno provocada por el iglesismo, la defección de los generales liberales del ejército federal y el triunfo no previsto de Díaz en la batalla de Tecoac."

Esta visión es refutada ampliamente por Perry, el cual realiza en la segunda parte de su libro un análisis inteligente, global y basado en fuentes de primera

10. Sobre esta caracterización de Cosío Villegas como historiador moralista e historiador con microscopio ver: Enrique Krauze, "Daniel Cosío Villegas" en Enrique Florescano y Ricardo Pérez Montfort, (compiladores), Historiadores de México en el siglo XX, Fondo de Cultura Económica-Consejo Nacional para la Cultura y las Artes, México, 1995, pp.87-121.

11. Daniel Cosío Villegas, "El Bailete", en Enrique Krauze, (compilador), Op.cit., pp. 65, 66. mano que demuestra como Porfirio Díaz tenía una clara estrategia militar, de carácter dinámico y en el ámbito nacional, que preveía todos los escenarios bélicos posibles y que se basaba fundamentalmente en la guerra de guerrillas y la ocupación progresiva de ciudades importantes, acompañada de una paulatina concentración de fuerzas que serviría para darle al gobierno el golpe final.

A lo largo de esta segunda parte el autor realiza un minucioso seguimiento de la insurrección armada, reconstruyendo cuidadosamente cada acción militar e insertándolas todas en el contexto global de la estrategia porfirista; así se estudia quiénes eran los insurrectos y cuáles eran sus formas de reclutamiento; de qué manera se dio el abastecimiento y financiamiento de la rebelión; cómo ocurrieron los movimientos de tropas y cuáles eran los objetivos militares y, algo que Perry considera esencial para el triunfo de la rebelión porfirista, la manera en que se desarrolló la guerra de guerrillas.

Para terminar se analiza el surgimiento, composición, objetivos y naturaleza del movimiento encabezado por el presidente de la Suprema Corte de Justicia, José María Iglesias. Aquí, aplicando las mismas técnicas utilizadas con anterioridad -un análisis a fondo de las fuentes primarias y secundarias pertinentes y una recons- 
trucción minuciosa de las maniobras políticas más importantes- Perry demuestra que el iglesismo no fue un movimiento hueco o sin importancia, como muchos lo han querido ver, y que su principal debilidad fue, paradójicamente, el decembrismo-de los militares, que con su actitud de no rebelarse en contra del gobierno de Lerdo hasta que éste no concluyera su mandato el día primero de diciembre de 1876, contribuyeron a la derrota final del iglesismo a manos de Porfirio Díaz, aspecto que se analiza en el último capítulo de la segunda parte.

De esta manera Perry demuestra a lo largo del libro una cosa que a nuestro juicio resulta relevante: casi ningún tema histórico puede considerarse como totalmente agotado, ni siquiera aquellos de naturaleza política o militar tratados anteriormente de manera exhaustiva por un historiador de renombre, como es el caso de la República Restaurada y la rebelión de Tuxtepec. A pesar de este panorama poco halagador, Perry tiene el mérito de otorgar al lector una nueva visión de ambos temas utilizando básicamente dos recursos: el estudio detallado e inteligente de un gran cúmulo de documentación primaria, destacando la utilización de la correspondencia personal de los actores, que es complementada con la revisión exhaustiva de las fuentes secundarias; todo esto le da un conocimiento profundo de las personas y sus motivaciones y una notable capacidad para el establecimiento y descripción minuciosos de los diversos hechos políticos y militares. El segundo recurso es igualmente importante: el acometimiento del tema desde una nueva perspectiva, tanto en el caso de la República Restaurada como en el de la rebelión de Tuxtepec; al abordar el período desde una visión ciertamente más crítica el autor trasciende la simple enumeración de hechos y otorga al lector un panorama diferente y revelador no sólo de este período de la historia sino de toda la vida política mexicana hasta el siglo XX.

Esto último constituye otro de los rasgos valiosos del libro, pues Perry no limita su estudio a los años de la República Restaurada, sino que ubica sus conclusiones en un contexto más amplio, señalando la importancia que ha tenido a lo largo de la historia la maquinaria política construida durante la República Restaurada, la cual, caracterizada por la centralización del poder, la monopolización del aparato público y la manipulación de las instituciones republicanas y liberales, fue perfeccionada durante el Porfiriato y sobrevivió casi íntegra a la Revolución de 1910, para ser adoptada por el partido oficial -"biznieto de Juárez"- y los gobiernos de México 
durante el siglo Xx, los cuales, como sus predecesores, sólo la han utilizado para favorecer el enriquecimiento de una pequeña élite "mientras las masas sufren pobreza y falta de participación" (p. 297).
Por esta razón, a juicio de Perry, los porfiristas se sentirían muy a gusto en el México contemporáneo y los revolucionarios no sólo se han replanteado su causa sino que han vuelto a tomar las armas. : 
